\title{
STUDIES OF SERUM ELECTROLYTES
}

\author{
ViII. The Concentration of Electrolytes and Non-Electrolytes \\ in the Serum Following Insulin Administration in Diabetic \\ Patients
}

\author{
By F. WILLIAM SUNDERMAN, J. HAROLD AUSTIN, AND \\ PRISCILLA WILLIAMS \\ (From the George S. Cox Research Institute, University of Pennsylvania and the \\ Pennsylvania Hospital, Philadelphia)
}

(Received for publication July 27,1932 )

Many studies have appeared in the literature on the effect of insulin on various constituents of the blood or blood serum of normal and diabetic individuals. These have been reviewed by Peters and Van Slyke (1). The evidence in the literature indicates that coincident with the fall of glucose, insulin produces a simultaneous fall in the concentration of inorganic phosphate, potassium and cholesterol in the serum. The amino acids appear to be lowered; lactic acid and nonprotein nitrogen apparently are not significantly altered; and the blood calcium concentration may be increased. There seems to be a difference of opinion as to the effect of insulin on the blood volume and the water content.

Gram (2) noted that the osmotic pressure of serum from diabetic patients was above the normal range. Hartmann and Darrow (3) observed that in two of their cases of diabetic acidosis in children who were treated with insulin, water, and carbohydrate, the observed osmotic pressure decreased as much as eighteen per cent following therapy. The freezing point of serum taken from control rabbits Haldane, Kay and Smith (4) found to be the same as from litter-mate rabbits after insulin convulsions, from which they conclude that insulin does not alter the osmotic pressure of the serum of normal rabbits.

Whether these changes described are caused by insulin alone or by other features of the total therapy, it is frequently difficult to determine. The effect of insulin on the blood serum may possibly be different in normal and in diabetic individuals, with and without ketosis, as well as in different animal species.

The following studies were planned to give a picture of the correlated changes occurring in the various electrolyte and non-electrolyte components of the blood serum of fasting diabetic patients with hyperglycemia but without ketosis, after a large dosage of insulin. 


\section{MATERIAL AND METHODS}

Seventeen observations have been made on patients suffering with severe diabetes mellitus who were attending the Metabolic Clinic at the Pennsylvania Hospital. After a period without insulin (generally twentyfour to forty-eight hours) long enough to induce a marked elevation of the blood sugar, and after an overnight fast, sufficient blood was taken by vein for the complete analyses. The patients, still fasting, were then given from 50 to 150 units of insulin, usually at one injection. In several instances, however, when no significant decrease in the value of the capillary blood sugar had occurred within one hour after the first injection of insulin, a second dose was administered. The total dosage is recorded in Table 1. Following insulin, the patients were permitted water as desired. At intervals of twenty minutes, finger-prick blood sugar values were obtained with a technique by which analytical results could be secured within fifteen to eighteen minutes after the withdrawal of the blood. As soon as the concentration of blood sugar had fallen to within normal limits (forty minutes to three hours) or upon the appearance of any symptoms of an insulin reaction, a second specimen of blood was removed by vein for complete analyses and the patient was returned to his usual regimen.

The analyses included serum chloride, carbon dioxide content, inorganic phosphate, total base, sodium, conductivity, freezing point, refractometric index, specific gravity, dry weight, cholesterol, nonprotein nitrogen, and blood sugar.

The chemical methods used in previous studies of this series were employed. Freezing point measurements were made, using refinements described recently by Sunderman (5). Conductivity measurements were made with a special conductivity assembly (6). For estimation of the protein of the serum from specific gravity, the equation of Moore and Van Slyke was employed (7). The Folin and Malmros sugar method (8) was used. The $\mathrm{pH}$ of the serum was measured in a single case with the glass electrode by the method of Stadie, O'Brien, and Laug (9).

\section{RESULTS}

The values of the individual analyses before and after insulin are recorded either in Figure 1 or in Table 1. In Figure 1 the dots represent original values before insulin, and the arrow points, values after insulin. In Table 1 are included dry weights and in many instances specific gravity of the sera. These data permit the calculation of individual components in relation to either dry residue or water. In our discussion of the data, however, the values are expressed in relation to total serum volume.

Blood sugar. The sugar values given in Figure 1 represent analyses made on whole venous blood without anticoagulant, the proteins having been precipitated by tungstic acid immediately after withdrawal of the 
F. W. SUNDERMAN, J. H. AUSTIN AND P. WILliAMS

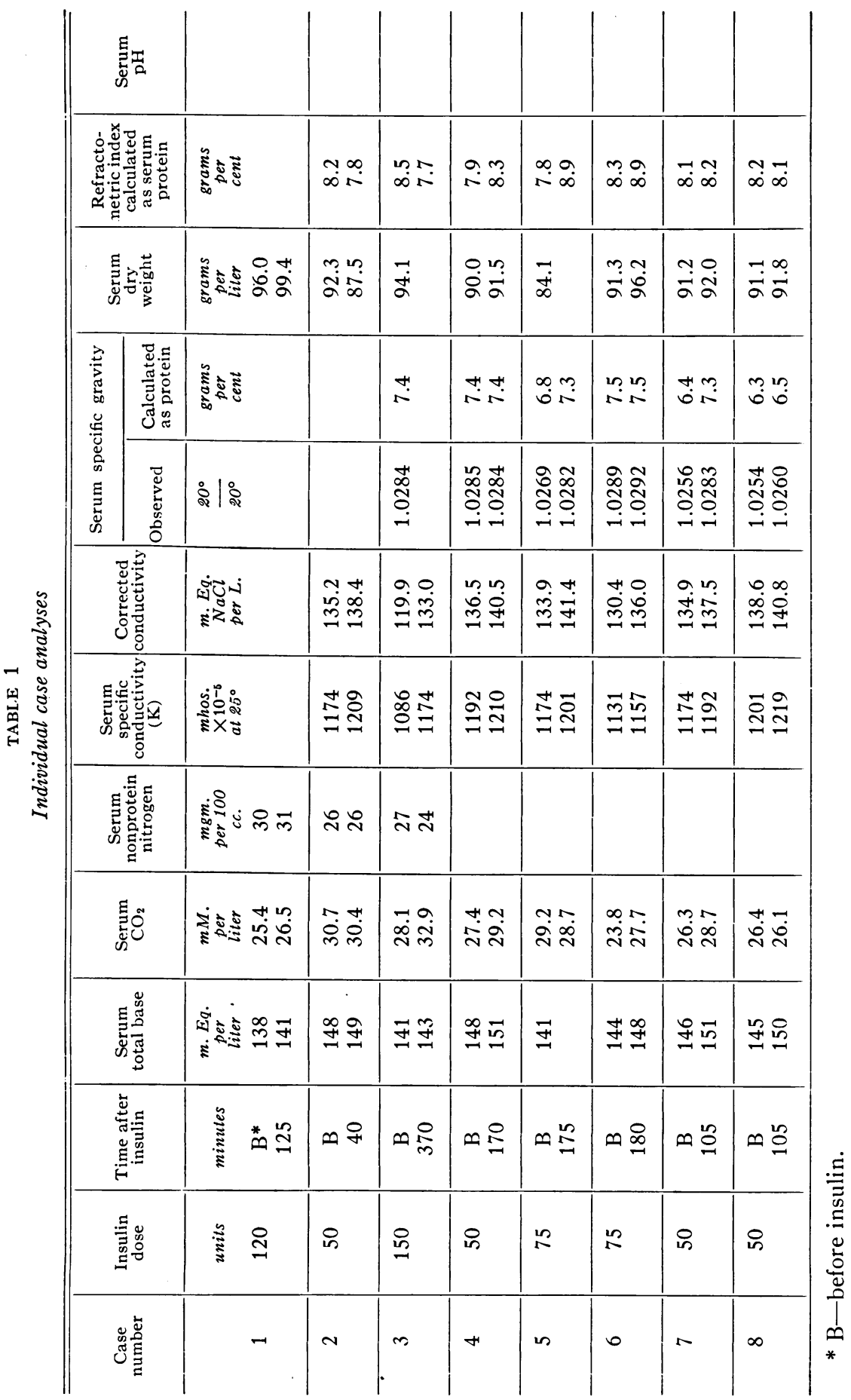




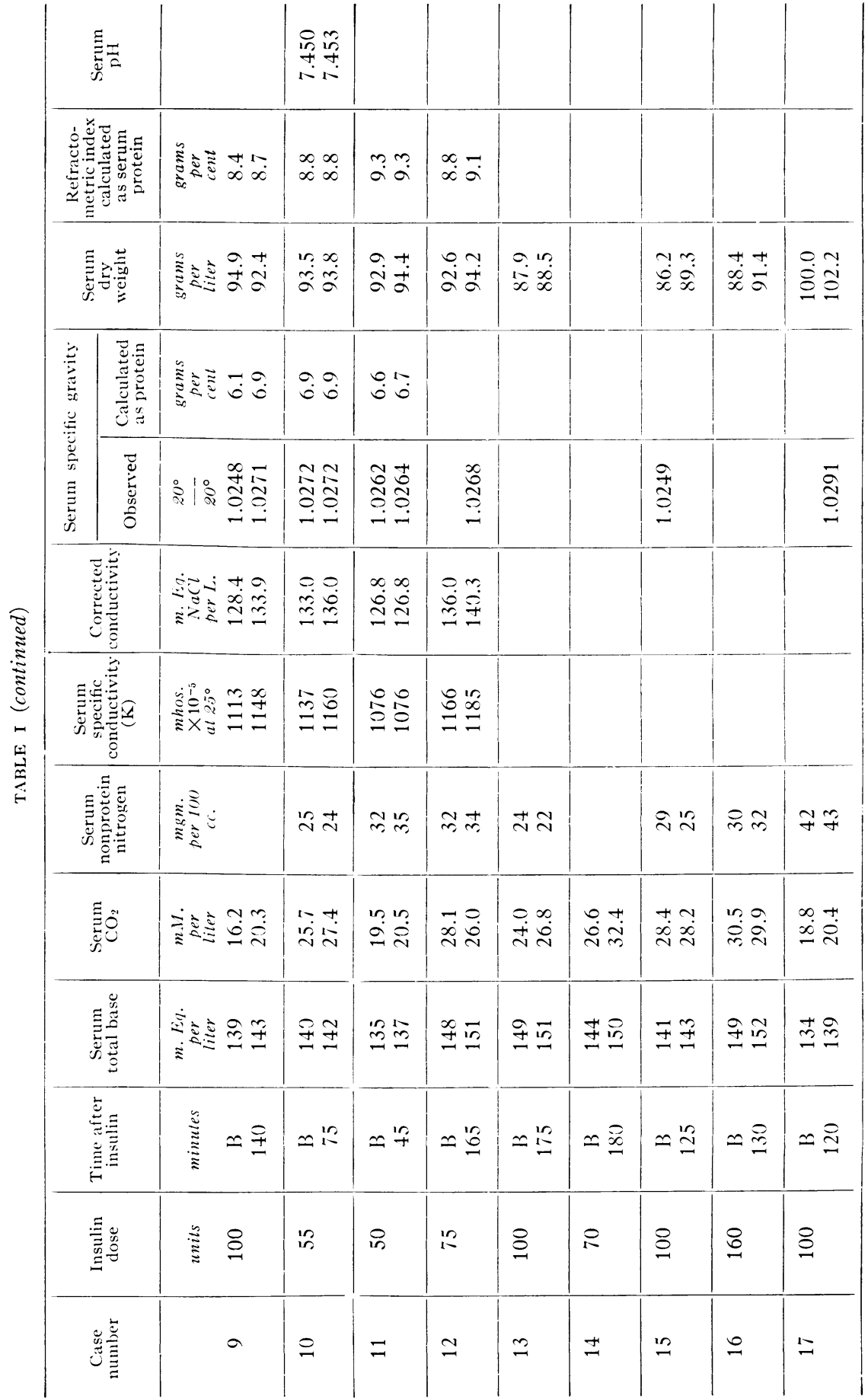


blood. The average diminution in the concentration of sugar was 178 mgm. per $100 \mathrm{cc}$. in 145 minutes. With four of the patients (Cases 9, $10,11,17)$ the study had to be terminated at a time when the concentration of sugar was above $200 \mathrm{mgm}$. per $100 \mathrm{cc}$. because of the appearance of shock-like reactions. In Cases 10,11, and 17 the ingestion of orange juice and in Case 9, the intravenous administration of glucose quickly relieved all symptoms of these reactions.

Cholesterol. All of the cholesterol concentrations of the serum obtained from the patients before the injection of insulin were above the normal range and varied from 196 to $322 \mathrm{mgm}$. per $100 \mathrm{cc}$. (Figure 1). Coincident with the fall in sugar the concentration of cholesterol consistently decreased.

Nonprotein nitrogen values (Table 1) were scattered about the normal range except in Case 17 in whom, both before and after insulin, this component was slightly above normal.

Solids. The concentration of total dry substances as shown in Table 1 exhibited no consistent change although there was a tendency for the specific gravity to increase. In a series of measurements on medical students, Dr. E. Harper working in our laboratory found the protein of the serum by means of specific gravity to be from 7.6 to 8.5 grams per cent with an average concentration of 7.84 grams per cent. The protein, calculated from the specific gravity in our series of observations was consistently below this normal range both before and after insulin.

Anions. It will be observed in Figure 1 that the inorganic phosphate of the serum decreased in each observation, as was anticipated from the studies of others. This simultaneous fall in the concentration of inorganic phosphate and sugar has led a number of investigators to suggest that insulin may be concerned in the formation of hexose-phosphoric esters in the tissues.

In each of our observations the chloride concentration in the serum increased after insulin administration, the percentile increase amounting to as much as nine per cent. It will be seen that in the original sera the chloride concentration was below the normal range in 13 out of 17 measurements. The chloride content of sera obtained after insulin increased either to or toward the normal range and in one observation above it. In 12 of 17 analyses the carbon dioxide content rose.

Cations. The measurements of the concentrations of cations in the sera were limited to total base and sodium. The results of the individual analyses of total base are given in Table 1 and of sodium in Figure 1. It will be seen that in 8 out of 13 observations the concentration of sodium in the serum before insulin administration was below the normal range. In each case after insulin the concentrations of sodium increased above the original values and in 5 analyses, above the normal range. The changes of total base were similar in direction and magnitude to 


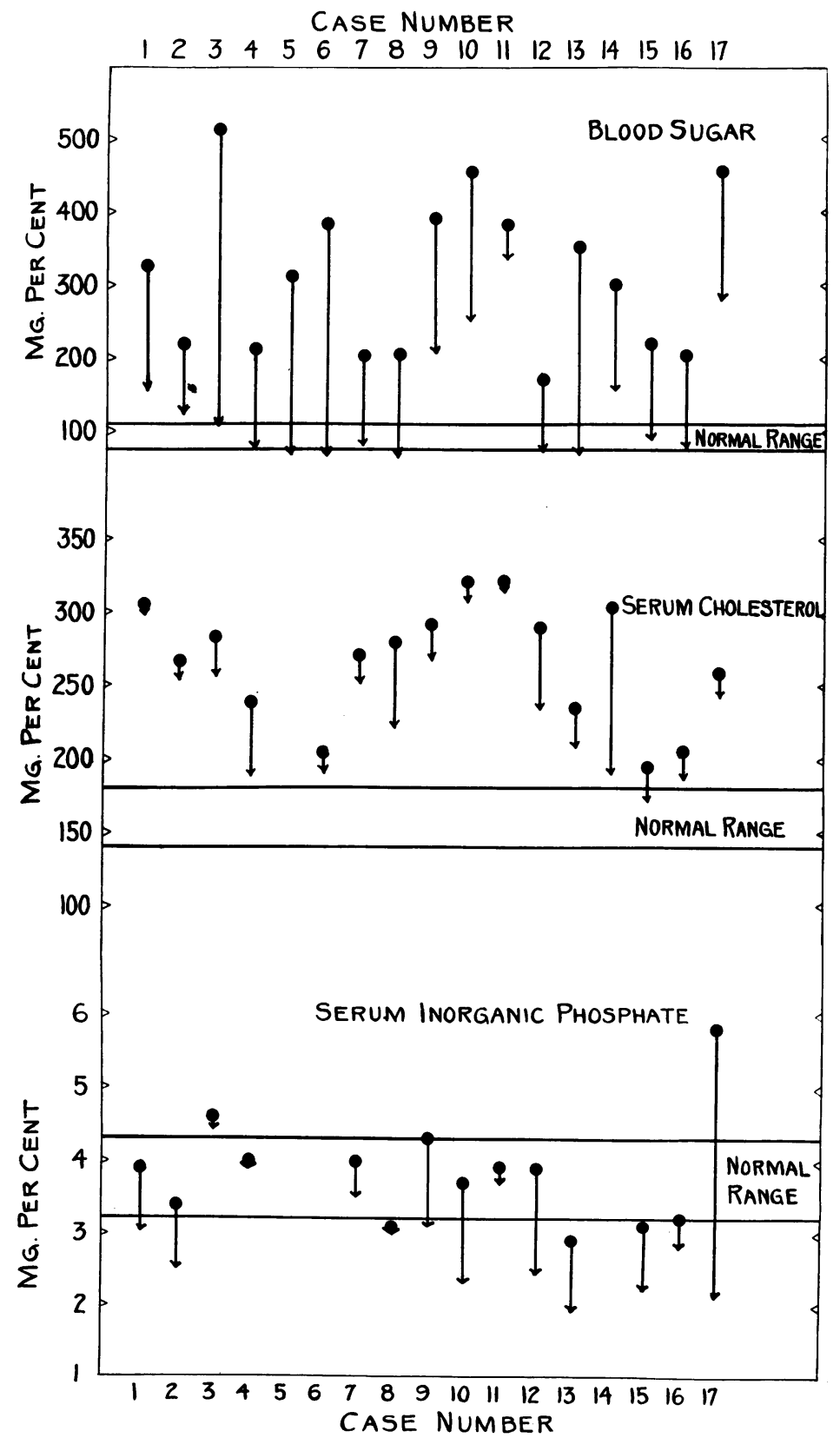

FIG. $1 A$ 
CASE NUMBER

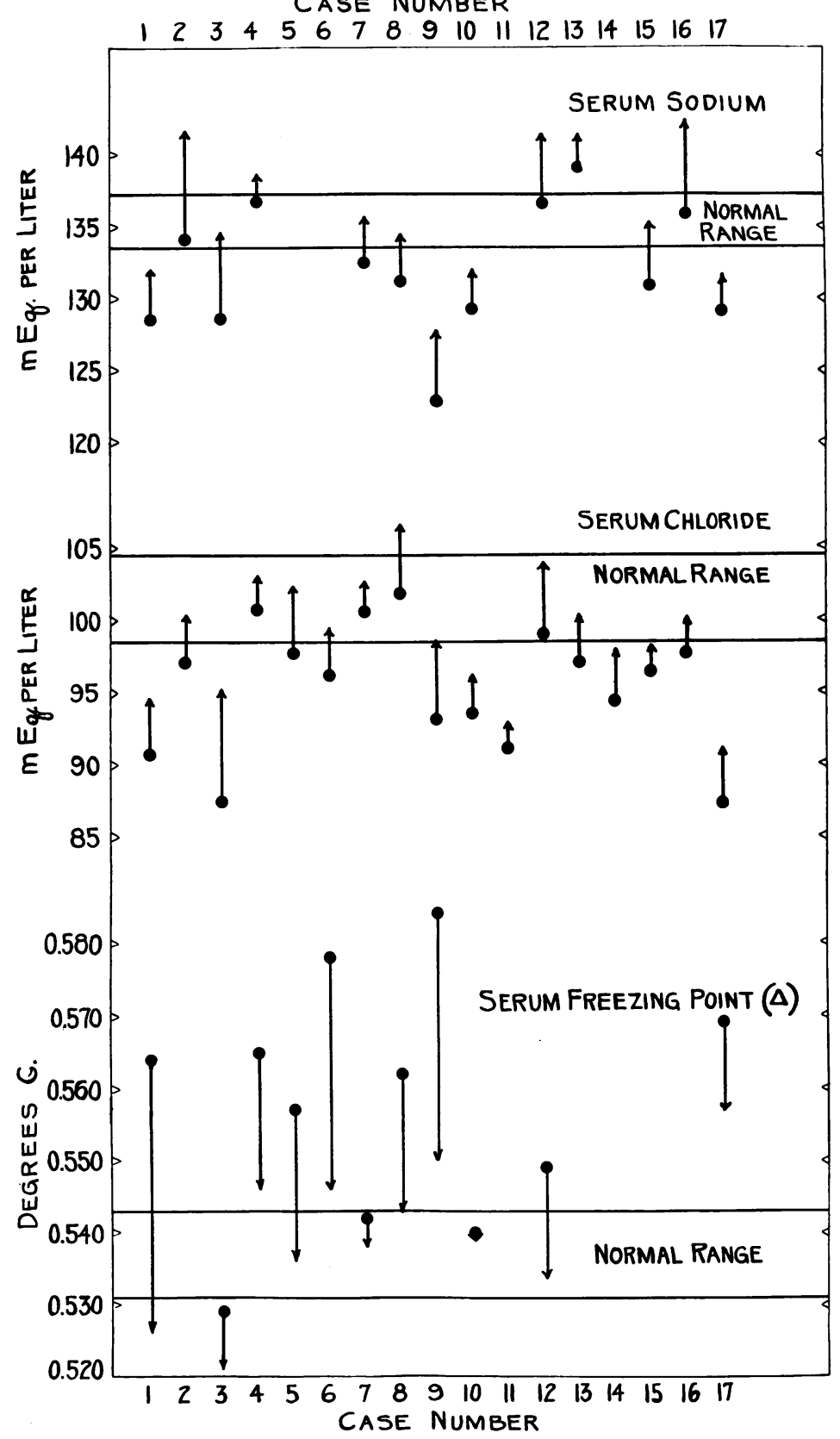

FIG. $1 B$ 
those of sodium. This was to be expected since the sodium in serum represents from 90 to 95 per cent of the total base.

The increase in electrolyte concentration was also reflected in increased conductivity values of the serum following insulin. The conductivity values given in Table 1 are expressed both in terms of specific conductivity and in $\mathrm{m}$. Eq. of $\mathrm{NaCl}$, corrected for protein by the Gram and Cullen formula (10).

Freezing point. The values for the depression of the freezing point of serum before and after insulin therapy are given in Figure 1. In all but one of the observations the freezing point depression was less after insulin, the maximum difference being as much as $0.034^{\circ} \mathrm{C}$. The freezing point depressions of the sera before insulin were generally greater than the normal range.

TABLE 2

The freezing point of serum of normal fasting individuals

\begin{tabular}{|c|c|}
\hline Specimen & $\stackrel{-1}{\circ}$ \\
\hline F.M.S. & 0.533 \\
\hline I'e... & 0.538 \\
\hline P.M. . . & 0.531 \\
\hline B.H. & 0.532 \\
\hline F.S.D. & 0.543 \\
\hline $\mathrm{Av}$ & (0).5354 \\
\hline
\end{tabular}

In Table 2 are given values for the freezing point of serum obtained from normal fasting individuals, using the refinements (5) of the StadieSunderman method (11). These values vary from $0.532^{\circ}$ to $0.543^{\circ}$ and are less than those recorded in the literature by observers who have used the Beckman method. Because of the supercooling and the increase of concentration produced by freezing out of solvent, the Beckman method tends to give unduly great depressions.

\section{DISCUSSION}

The reciprocal change of glucose and electrolytes observed in the blood serum appears to be similar to the inverse changes described by Herrick (12) following a sugar tolerance test and by $\mathrm{Ni}$ (13) following extirpation of the pancreas in a dog. In Ni's experiments, after pancreatectomy in the $\operatorname{dog}$ there was a reduction of the chloride of serum associated with an increased concentration of sugar. When insulin was given, sugar decreased and chloride rose. He estimated that only about 50 per cent of the osmotic pressure change produced by the blood sugar rise after pancreatectomy was compensated for by the decrease in chloride. From estimations of the osmolar changes owing to the decrease in glucose and the increase of electrolytes in our observations it would appear that the increase of electrolytes only partly compensated 
the loss of glucose. As direct evidence of this there was, as a rule, some fall in the osmolar concentration, as measured directly by the freezing point. The studies in the literature and our observations would suggest that when the blood sugar falls or rises some tissue or body fluid, concerning the identity of which we have no evidence, is capable of coincidently releasing electrolyte into or withdrawing electrolyte from the serum.

The decreased concentration of cholesterol in the serum following insulin is consistent with the evidence in the literature (Blix (14)), (Christomanos (15)), of the reduction not only of cholesterol but of lipoids in general. While Nitzescu, Popescu-Inotesti, and Cadariu (16) found the hyperlipemia of both experimental and clinical diabetes to be reduced by insulin, no effect on the cholesterol content was observed in normal individuals. We have made no measurements of the effect of insulin on the serum of normal subjects. Rabinowitch (17) reported two hyperlipemic diabetic subjects in whom a rapid fall in the blood fat occurred after insulin therapy.

In the four observations in which shock-like reactions appeared at hyperglycemic levels, the question might be raised as to whether the sugar in arterial blood was also elevated at the time of the reactions. We have no analyses of the sugar of arterial blood in these patients, but the values for capillary blood sugar which were obtained at intervals of twenty minutes in each experiment were always above the final venous blood sugar values.

Shock-like reactions at high sugar values occurred in our patients, in four out of six instances, when high initial sugar values (above $380 \mathrm{mgm}$. per $100 \mathrm{cc}$.) were associated with rapid fall $(1 \mathrm{mgm}$. per minute or greater). It seems that neither high initial blood sugar nor rapid rate of fall will independently induce reactions at high sugar levels but that the combination of these two factors may do so. It is also evident that reactions which we did not distinguish from ordinary insulin reactions and which were promptly relieved by the administration of carbohydrate can develop while the blood sugar concentration is above $200 \mathrm{mgm}$. per cent under the conditions of these experiments. As Joslin (18) points out this combination of events is extremely rare after insulin administration in ordinary clinical practice.

\section{SUMMARY}

Insulin was withheld for 18 or more hours from 17 patients with severe diabetes mellitus. After an overnight fast blood was removed for the analyses and the patients were given approximately a day's maintenance dosage of insulin, usually at one injection. Food was withheld and capillary blood sugar measurements were made at intervals of twenty minutes until the concentration of blood sugar reached a normal level or 
until the patients experienced early symptoms of an insulin reaction. At this time blood was again removed for analyses.

The concentration of inorganic phosphate and cholesterol of the serum after the insulin administration decreased, as had been anticipated. The concentration of total base, sodium, chloride, and specific conductivity of the serum following the insulin injection increased. As measured by freezing point, the osmolar concentration of the serum following insulin administration generally decreased, suggesting that the increased concentration of electrolytes did not compensate completely for the decreased concentration of the blood sugar. Specific gravity tended to increase above the original value after the administration of insulin. The final picture, we believe, represents a change in the serum toward the normal, not only in the fall of glucose and cholesterol, but also in the rise of sodium and chloride and the diminished osmolar concentration, as measured by the freezing point.

Shock-like reactions in four of our patients occurred at a time when the concentration of the blood sugar was above $200 \mathrm{mgm}$. per cent. These reactions, therefore, do not seem to be necessarily caused by a hypoglycemic state. They occurred when the blood sugar fell rapidly from an initially very high level.

\section{BIBLIOGRAPHY}

1. Peters, J. P., and Van Slyke, D. D., Quantitative Clinical Chemistry. Volume I. Interpretations. The Williams and Wilkins Co., Baltimore, 1931.

2. Gram, H. C., J. Biol. Chem., 1923, lvi, 593. Observations on the Regulation of Osmotic Pressure (Conductivity, Chlorides, Freezing Point, and Proteins of Serum).

3. Hartmann, A. F., and I)arrow, D. C., J. Clin. Invest., 1928, vi, 257. Chemical Changes Occurring in the Body as the Result of Certain I)iseases. III. The Composition of the Plasma in Severe I)iabetic Acidosis and the Changes Taking Place During Recovery.

4. Haldane, J. B. S., Kay, H. D., and Smith, IV., J. Physiol., 1924, lix, 193. The Effect of Insulin on Blood Volume.

5. Sunderman, F. William, J. Biol. Chem., 1932, xcri, 271. The Osmotic Behavior of Water of Blood Serum.

6. Sunderman, F. William, J. Biol. Chem., 1930, lxxxriii, 61. A Sixty Cycle Conductivity Assembly for Biological Fluids.

7. Moore, N. S., and Van Slyke, D. D., J. Clin. Invest., 1930, viii, 337. The Relationships between Plasma Specific Gravity, Plasma Protein Content, and Edema in Nephritis.

8. Folin, O., and Malmros, H., J. Biol. Chem., 1929, 1xxxiii, 115. An Improved Form of Folin's Micro Method for Blood Sugar Determinations.

9. Stadie, W. C., O'Brien, H., and Laug, E. P., J. Biol. Chem., 1931, xci, 243. Determination of the $\mathrm{pH}$ of Serum at $38^{\circ}$ with the Glass Electrode and an Improved Electron Tube Potientiometer.

10. Gram, H. C., and Cullen, G. E., J. Biol. Chem., 1923, 1vii, 477. The Accuracy of the "Ionometric" Method and of the Protein Correction in Measuring Serum Conductivity. 
11. Stadie, W. C. and Sunderman, F. William, J. Biol. Chem., 1931, xci, 217. A Method for the Determination of the Freezing Point Depression of Aqueous Solutions Particularly Those Containing Protein.

12. Herrick, W. W., J. Lab. and Clin. Med., 1924, ix, 458. The Reciprocal Relationship of Chlorides and Glucose in the Blood.

13. Ni, T. G., Am. J. Physiol., 1926, lxxviii, 158. On the Inverse Change Between the Concentration of Glucose and Chloride in the Blood.

14. Blix, G., Acta med. Scandinav., 1926, lxiv, 142. Studies on Diabetic Lipemia.

15. Christomanos, A. A., Biochem. Ztschr., 1929, ccxiv, 482. Über den Einfluss des Insulins auf die Fettverteilung im Serum.

16. Nitzescu, I. I., Popescu-Inotesti, C., and Cadariu, I., Compt. rend. Soc. de biol., 1924, xc, 1067. Cholestérinémie et cholestérolyse dans le diabète expérimental.

17. Rabinowitch, I. M., Am. J. Med. Sci., 1928, clxxvi, 489. Unusual Fat Metabolism in a Case of Diabetes Mellitus.

18. Joslin, E. P., The Treatment of Diabetes Mellitus. Lea and Febiger, Philadelphia, 1928, 4th ed. 